\title{
Expression of Cryptantigen Th on Paroxysmal Nocturnal Hemoglobinuria Erythrocytes in Association with a Hemolytic Exacerbation
}

\author{
Hideki Nakakuma, * Michihiro Hidaka, * Shoichi Nagakura, * Yoko Nishimura, ${ }^{\star}$ Norihiro Iwamoto, ${ }^{\circ}$ Kentaro Horikawa, * \\ Tatsuya Kawaguchi, * Tadashi Kagimoto, ${ }^{\mathbf{5}}$ and Kiyoshi Takatsuki* \\ *The Second Department of Internal Medicine, ${ }^{\ddagger}$ Department of Blood Transfusion Service, Kumamoto University School of Medicine; \\ and ${ }^{8}$ College of Medical Science, Kumamoto University, Kumamoto 860, Japan
}

\begin{abstract}
Paroxysmal nocturnal hemoglobinuria (PNH) erythrocytes lack complement regulatory membrane proteins and are susceptible to complement. Although the critical role of complement in intravascular hemolysis in PNH is accepted, the precise mechanism of complement activation in vivo is unknown. Accordingly, in a PNH patient who was suffering from a hemolytic precipitation soon after a common coldlike upper respiratory infection, we analyzed the erythrocytes with lectins and by flow cytometry to detect membrane alteration that lead to complement activation. The lectin reactivity of erythrocytes showed the expression of cryptantigen Th. The patient serum at the time of the hemolysis induced the expression of Th on erythrocytes from PNH patients and from healthy volunteers in vitro, whereas neither the patient serum after recovery from the hemolysis nor blood type-matched control serum from healthy donor showed this activity. Moreover, autologous serum selectively hemolyzed $\mathrm{Th}^{+}$PNH erythrocytes, but not Th ${ }^{-}$PNH erythrocytes, or $\mathrm{Th}^{+}$control erythrocytes. Hemolysis was not observed either in complement-inactivated serum or in blood type-matched cord blood serum, which lacks natural antibodies to cryptantigens. These findings indicate that the immunoreaction of infection-induced Th with natural antibody on PNH erythrocytes is a trigger of the complement activation, leading to intravascular hemolysis. (J. Clin. Invest. 1995. 96:201-206.) Key words: paroxysmal nocturnal hemoglobinuria • hemolysis - complement activation - cryptantigen $\cdot$ infection
\end{abstract}

\section{Introduction}

Paroxysmal nocturnal hemoglobinuria (PNH) ${ }^{1}$ is an acquired stem cell disorder which manifests hemolytic anemia, frequent

Address correspondence to Hideki Nakakuma, Associate Professor of Medicine, The Second Department of Internal Medicine, Kumamoto University School of Medicine, Honjo 1-1-1, Kumamoto 860, Japan. Phone:81-96-373-5155; FAX:81-96-363-5265.

Received for publication 26 October 1994 and accepted in revised form 24 January 1995.

1. Abbreviations used in this paper: CAP, cryptantigen-associated precipitation; DAF, decay-accelerating factor; PE, phycoerythrin; PNH, paroxysmal nocturnal hemoglobinuria.

J. Clin. Invest.

(C) The American Society for Clinical Investigation, Inc. 0021-9738/95/07/0201/06 \$2.00

Volume 96, July 1995, 201-206 episodes of infection, venous thrombosis, myelodysplasia, and leukemic conversion (1-4). The hemolysis is based on an enhanced susceptibility of erythrocytes to complement $(2,3)$. The abnormal sensitivity is explained by a deficiency in the complement regulatory membrane proteins such as decay-accelerating factor (DAF) and CD59, which use glycosylphosphatidylinositol (GPI) anchor to attach to the membrane of blood cells (3). The deficiency is attributed to a synthetic defect of the anchor due to the impaired transfer of $\mathrm{N}$-acetylglucosamine to phosphatidylinositol, a precursor of the anchor $(5,6)$. The molecular nature of membrane disorders which cause abnormal sensitivity to complement has thus been clarified. The lack of GPI-anchored proteins therefore has a diagnostic value in PNH, showing that affected erythrocytes are ready to undergo hemolysis. Apart from the nature of affected erythrocytes, however, other factors that induce intravascular activation of complement are required to explain the actual hemolysis such as episodic hemolysis ("paroxysmal"), notable hemolysis at night ("nocturnal"), and persistent mild hemolysis ("hemoglobinuria") $(2,4)$. Episodic hemolysis, often precipitated by infections, is distinct because of the rapid induction of serious anemia and the damage to critical organs (4). Accordingly, clarification of the mechanism that activates complement is a matter of great importance.

The most likely potential trigger of the complement activation that leads to hemolysis is generally an antigen-antibody reaction on erythrocytes (7). The reaction requires either the expression of new antigens on erythrocytes or the production of autoantibodies to erythrocytes, the latter is often noted in autoimmune hemolytic anemia (7). Structural alterations of membranes induce new antigens, some of which are detectable by in vitro agglutination either with natural polyagglutinins (IgM) in serum or with lectins which recognize specific sugar architecture (8-10). For example, infections infrequently disclose cryptantigens on blood cells by releasing nonreducing terminal carbohydrates of membrane glycoconjugates $(8-10)$. Erythrocytes with these antigens become polyagglutinable and are rarely involved in hemolytic anemia, although the precise relationship is not clear (8-12). Thus, the expression of cryptantigens on erythrocytes may cause an immune reaction with natural antibodies, leading to complement activation on the erythrocytes, and resulting in hemolysis, especially when the erythrocytes are inherently susceptible to complement. Accordingly, we investigated the involvement of cryptantigens in PNH hemolysis.

\section{Methods}

Patient profile. We present the history of a patient who experienced infection-associated hemolytic precipitation and whose erythrocytes at the time of the hemolytic episode were subsequently analyzed. In April 1992, a 16-yr-old adolescent complained of dark urine after having an 


\begin{tabular}{|c|c|c|c|c|c|c|c|c|}
\hline & $3 / 2$ & $3 / 29$ & $4 / 2$ & $4 / 6$ & $4 / 11$ & $4 / 18$ & $5 / 2$ & $5 / 11$ \\
\hline WBC $\left(10^{9} /\right.$ liter $)$ & 3.1 & 5.3 & 5.3 & 6.9 & 6.2 & 4.4 & 5.1 & 4.2 \\
\hline RBC $\left(10^{12} /\right.$ liter $)$ & 3.43 & 2.88 & 1.81 & 2.41 & 2.49 & 2.71 & 3.28 & 3.55 \\
\hline $\mathrm{Hb}$ (g/liter) & 82 & 84 & 56 & 75 & 79 & 87 & 104 & 108 \\
\hline Plts $\left(10^{9} /\right.$ liter $)$ & 228 & 242 & 213 & 204 & 204 & 178 & 192 & 214 \\
\hline CRP $(<0.3 \mathrm{mg} / \mathrm{dl})$ & & 0.88 & 0.58 & 0.6 & 0.28 & 0.25 & 0.26 & \\
\hline AST (5-40 U/l) & 53 & 241 & 208 & 123 & 108 & 91 & 68 & \\
\hline ALT $(0-40 \mathrm{U} / \mathrm{l})$ & 36 & 42 & 48 & 27 & 23 & 22 & 30 & \\
\hline T-bil $(0.3-1.2 \mathrm{mg} / \mathrm{dl})$ & 1.0 & 3.0 & & 2.3 & 2.2 & 1.5 & 1.2 & 1.3 \\
\hline LDH (236-427 U/liter) & 2,765 & 10,990 & 14,560 & 8,600 & 6,725 & 5,050 & 3,845 & 3,831 \\
\hline Haptoglobin $(0.25-2.03 \mathrm{~g} /$ liter $)$ & & 0.01 & & $<0.01$ & & $<0.01$ & & \\
\hline Free $\mathrm{Hb}(<0.11 \mathrm{~g} /$ liter $)$ & & 4.4 & 2.6 & & 1.8 & & & \\
\hline Coombs' test & & & - & & & & & \\
\hline $\mathrm{CH}_{50}(28-45 \mathrm{U} / \mathrm{ml})$ & & & 30 & & & & & \\
\hline
\end{tabular}

WBC, white blood cells; RBC, red blood cells; Hb, hemoglobin; Plts, platelets; CRP, C-reactive protein; AST, aspartate aminotransferase; ALT, alanine aminotransferase; T-bil, total bilirubin; $\mathrm{LDH}$, lactate dehydrogenase.

upper respiratory infection. Laboratory findings showed pancytopenia and Coombs' negative intravascular hemolysis, and in vitro hemolysis tests, i.e., the sugar-water test and Ham's acidified serum test, were positive. Flow cytometry detected affected erythrocytes negative for DAF and CD59. Bone marrow aspiration showed enhanced erythropoiesis without atypical cells. The patient was then diagnosed as having PNH. Infusion with haptoglobin, transfusion with washed erythrocytes, and treatment with prednisolone induced clinical improvement. Since then, he has been in clinically good condition for $\sim 2 \mathrm{y}$, although he experienced one episode of minor abdominal thrombosis. On March 25 1994, he again had a common cold-like upper respiratory infection, and $3 \mathrm{~d}$ later, he noticed obvious hemoglobinuria, despite the mild symptoms of the infection. Since clinical findings and laboratory data showed marked intravascular hemolysis (hemoglobin fell from 84 to $56 \mathrm{~g} /$ liter), he was admitted to our hospital. Chronological laboratory data are summarized in Table I.

Chemicals. The lectins Arachis hypogaea, Glycine soja, and Salvia sclarea were obtained from Gamma Biologicals, Inc. (Houston, TX). Griffonia simplicifolia II was obtained from E. Y. Laboratories, Inc. (San Mateo, CA). Polybrene (hexadimethrine bromide; 1,5-Dimethyl1,5-diazaundeca methylene polymethobromide) and ficin protease were obtained from Sigma Chemical Co. (St. Louis, MO). Streptococcal sialidase (EC 3.2.1.18) was purchased from Seikagaku Corp. (Tokyo, Japan). EGTA and EDTA were obtained from Nacalai Tesque (Kyoto, Japan). Mouse anti-human DAF $\mathrm{mAb}\left(\mathrm{IgG}_{1}\right)$ was purchased from Wako Pure Chemical Industries (Osaka, Japan). FITC- and phycoerythrin (PE)-conjugated goat anti-mouse IgG were, respectively, obtained from Zymed Laboratories, Inc. (San Francisco, CA) and Jackson Immunoresearch Laboratories Inc. (West Grove, PA). FITC-conjugated Arachis hypogaea lectin was purchased from Honen Corp. (Tokyo, Japan). Mouse anti-human CD59 $\mathrm{mAb}\left(\mathrm{IgG}_{1}\right)$ was a gift from Dr. $\mathrm{M}$ Tomita of Showa University, (Tokyo, Japan) (5). An aliquot of antiCD59 mAb was conjugated with PE by incubation with pyridyl disulfide-activated phycobiliprotein, according to the manufacturer's instructions (Pierce Chemical Co., Rockford, IL).

Lectin reactivity of polyagglutinable erythrocytes. Throughout the study, serologic tests were performed according to the procedures outlined in the American Association of Blood Banks Technical Manual (13). Polyagglutination tests were based on the standard lectin procedures (14). Moreover, every procedure was performed aseptically as far as was practicable. After informed consent was given, heparinized erythrocytes were obtained from four healthy adult volunteers and from three patients with PNH including the patient described in the patient profile. The cells were soon washed three times with PBS containing 1
mM EDTA. Just before use, the erythrocytes were washed three more times with PBS alone and adjusted to a concentration of $3-4 \%$ in suspension with PBS. They were then subjected to a polyagglutination test with a panel of the lectins (Table II), except for Vicia cretica. In brief, one drop of cell suspension was mixed with two drops of each lectin reagent at room temperature $\left(20^{\circ} \mathrm{C}\right)$ for $10 \mathrm{~min}$. The cells were then centrifuged for $20 \mathrm{~s}$ at $3,400 \mathrm{rpm}$ and examined macroscopically for agglutination. For further characterization of the erythrocyte membrane, both the reactivity with $0.05 \%$ polybrene which reflects the content of surface sialic acid and the effects of a protease (ficin) on reactivity with Arachis hypogaea were examined (14). For protease treatment, cells were incubated with $0.05 \%$ ficin in PBS at $37^{\circ} \mathrm{C}$ for $15 \min (13)$.

Induction of Th antigen on erythrocytes with serum or sialidase in vitro. Aliquots of $\mathrm{PNH}$ and control erythrocytes were incubated at $37^{\circ} \mathrm{C}$ for $24 \mathrm{~h}$ with either serum obtained from the patient at the time of the hemolytic episode, serum from the same patient after recovery from the episode, serum from blood type ( $\mathrm{ABO}, \mathrm{Rh})$-matched healthy adult volunteers, or serum from blood type-matched cord blood. The induction of Th on erythrocytes was then investigated by determining reactivity with the lectins, while concomitant hemolysis was evaluated macroscopically. Other erythrocytes were treated with sialidase at $37^{\circ} \mathrm{C}$ for up to $2 \mathrm{~h}$, as described previously (15): $100 \mathrm{ml}$ of packed cells/1 mU of enzyme per $1 \mathrm{ml}$ of $0.1 \mathrm{M}$ PBS ( $\mathrm{pH} 6.5$ ). By analyzing the cells with the lectins, we then determined the most appropriate incubation time for the selective disclosure of $\mathrm{Th}$ with sialidase. $\mathrm{Th}^{+}$erythrocytes were subsequently subjected to in vitro hemolysis assay and to membrane analysis by flow cytometry.

Table II. Lectin Reactivity of Polyagglutinable Erythrocytes

\begin{tabular}{lccccccc}
\hline & $\mathrm{T}$ & $\mathrm{Tk}$ & $\mathrm{Th}$ & $\mathrm{Tx}$ & $\mathrm{Tn}$ & $\mathrm{Cad}$ & $\mathrm{Pt}^{*}$ \\
\hline Arachis hypogaea & + & + & + & + & - & - & + \\
$\quad$ + ficin treatment & + & ++ & - & + & - & - & - \\
Glycine soja & + & - & - & - & + & + & - \\
Griffonia simplicifolia II & - & + & - & - & - & - & - \\
Salvia sclarea & - & - & - & - & + & - & - \\
Vicia cretica & + & - & + & - & - & - & N.T. $^{\ddagger}$ \\
Polybrene & - & + & + & + & - & + & + \\
\end{tabular}

* PNH patient with hemolytic precipitation. ${ }^{\ddagger}$ Not tested. 


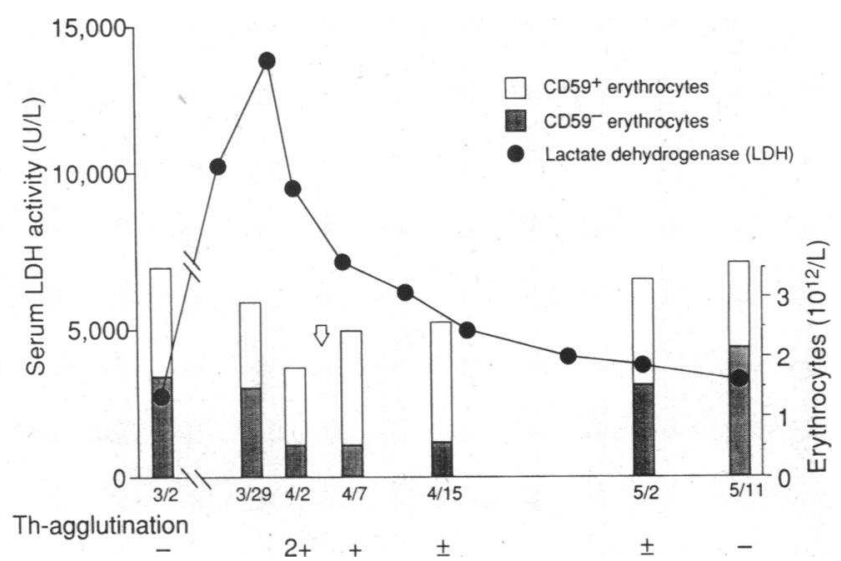

Figure 1. Correlation of serum lactate dehydrogenase activity ( $L D H$, $\bullet$ ), population of CD59-negative erythrocytes ( $\square$ ), and Th agglutination in infection-associated hemolytic precipitation. Open arrow indicates transfusion with washed erythrocytes. The numbers beneath the abscissa represent the grade of Th-agglutination of erythrocytes (13).

Hemolysis assay. The Th-positive erythrocytes induced by sialidase $\left(2.6 \times 10^{8}\right.$ cells in $\left.100 \mu \mathrm{l}\right)$ were incubated with four vol $(400 \mu \mathrm{l})$ of autologous serum at $37^{\circ} \mathrm{C}$ for up to $24 \mathrm{~h}$. Serum was prepared just before use. The extent of hemolysis was quantitatively determined by spectrophotometric measurement of hemoglobin liberated into the supernatant at $540 \mathrm{~nm}$, as described previously $(16) . \mathrm{OD}_{540}$ was then converted to percent hemolysis to represent hemolytic activity, using a newly prepared standard curve. To examine the involvement of complement in the process of hemolysis, complement in serum was inactivated by heating at $56^{\circ} \mathrm{C}$ for $30 \mathrm{~min}$ or by chelation with EDTA and EGTA (both $5 \mathrm{mM}$ ) (16). Each assay was performed in triplicate.

Flow cytometry. The cell surface was also analyzed by flow cytometry, as described previously (17). In brief, erythrocytes $\left(10^{7}\right)$ were incubated with anti-DAF mAb or with anti-CD59 $\mathrm{mAb}$ at $4^{\circ} \mathrm{C}$ for 30 $\mathrm{min}$ and labeled with FITC-conjugated anti-mouse IgG. The cells were then analyzed with a FACScan ${ }^{\oplus}$ (Becton Dickinson Laboratories, Mountain View, CA). For two-color analysis, the cells that expressed Th alone among the cryptantigens were incubated with FITC-conjugated Arachis hypogaea lectin to label $\mathrm{Th}$; the cells were subsequently incubated with either PE-conjugated anti-CD59 mAb or with both anti-DAF $\mathrm{mAb}$ and PE-conjugated anti-mouse IgG.

\section{Results}

Infection-associated hemolytic precipitation. Table I shows the intravascular hemolytic episode soon after upper respiratory infection, despite the mild symptoms of infection. Compared with serious hemolysis (when hemoglobin fell from 84 to 56), the consumption of complement (represented by $\mathrm{CH}_{50}$ ) was not remarkable. Fig. 1 shows the close correlation between the hemolysis and the decrease of CD59-negative erythrocytes in the peripheral blood.

Appearance of cryptantigen Th on erythrocytes. Cell surface analysis with Arachis hypogaea lectin detected agglutinable erythrocytes in the PNH patient (described in the profile) at the time of hemolytic precipitation (Table II). The erythrocytes did not react with either Glycine soja, Grifonia simplicifolia II, or Salvia sclarea, but showed normal reactivity with polybrene. The reactivity with Arachis hypogaea disappeared after ficin treatment. The findings suggest expression of Th on the erythrocytes, although Vicia cretica was not tested (Table II). The appearance of $\mathrm{Th}^{+}$erythrocytes was closely associated with
Table III. Induction of Th on Erythrocytes with Serum and Concomitant Hemolysis*

\begin{tabular}{|c|c|c|c|c|}
\hline \multirow[b]{2}{*}{ Serum } & \multirow[b]{2}{*}{ Induction } & \multicolumn{3}{|c|}{ Erythrocytes } \\
\hline & & $\begin{array}{l}\text { From the patient } \\
\text { at the time of } \\
\text { hemolytic } \\
\text { episode }\end{array}$ & $\begin{array}{c}\text { From } \\
\text { another } \\
\text { patient } \\
\text { with PNH }\end{array}$ & $\begin{array}{l}\text { From } \\
\text { healthy } \\
\text { donor }\end{array}$ \\
\hline \multirow{2}{*}{$\begin{array}{l}\text { From the patient } \\
\text { at time of } \\
\text { hemolytic episode }\end{array}$} & Hemolysis & + & + & - \\
\hline & Th expression & + & + & + \\
\hline \multirow{2}{*}{$\begin{array}{l}\text { The patient after } \\
\text { recovery }\end{array}$} & Hemolysis & + & - & - \\
\hline & Th expression & + & - & - \\
\hline \multirow[t]{2}{*}{ Healthy donor ${ }^{\ddagger}$} & Hemolysis & + & - & - \\
\hline & Th expression & + & - & - \\
\hline \multirow[t]{2}{*}{ Cord blood } & Hemolysis & - & - & - \\
\hline & Th expression & + & - & - \\
\hline
\end{tabular}

* All sera and erythrocytes were obtained from individuals with $\mathrm{O}(\mathrm{H})$ blood group antigen. ${ }^{\ddagger}$ Representative of four healthy donors.

both the hemolytic precipitation and the decrease of $\mathrm{CD}^{-} 9^{-}$ cells (Fig. 1). Polyagglutination with the erythrocytes of March 29, 1994 was not tested.

Th-induction activity in serum which was obtained at the time of the hemolytic precipitation. In addition to erythrocytes that included $\mathrm{Th}^{+}$cells from the patient (blood type: $\mathrm{O}, \mathrm{Rh}^{+}$), blood type-matched erythrocytes from another PNH patient who was not currently experiencing a hemolytic episode, and erythrocytes from a healthy donor were incubated with various sera, as shown in Table III. Incubation with the serum obtained from the patient at the time of the hemolytic episode induced Th on erythrocytes, whereas serum from the same patient after recovery from the episode, sera from healthy donors, or cord blood serum did not show such activity. The supernatant of hemolyzed $\mathrm{Th}^{+}$PNH erythrocytes in autologous serum, which was obtained after recovery from the hemolytic episode, did not induce Th on erythrocytes (in the experiment described later). On the other hand, concomitant hemolysis was observed in association -with Th expression on erythrocytes from PNH patients, while the erythrocytes from the healthy control were intact despite the presence of $\mathrm{Th}^{+}$cells. Even the $\mathrm{Th}^{+}$erythrocytes from PNH patients were not hemolyzed in either complement-inactivated serum or cord blood serum.

Sialidase-induced expression of Th on erythrocytes. Sialidase-treated erythrocytes became agglutinable first with Arachis hypogaea alone and subsequently further with Glycine soja (Table IV). The expressed antigens were identified as Th and $T$, respectively, according to their lectin reactivity. The cryptantigens were expressed on PNH erythrocytes more rapidly than on control cells. In particular, cryptantigen $\mathrm{T}$ was not expressed on control cells for $2 \mathrm{~h}$. In addition to streptococcal sialidase, a sialidase of Clostridium perfringens also showed the activity. These findings are consistent with previous report (15). With the erythrocytes that expressed Th alone after 60-min treatment, the results of polyagglutination tests were $4+$ (maximum grade) for both control and PNH cells (Table IV), whereas flow cytometry showed Th expression on virtually all of the erythrocytes (Figs. $2 A$ and 3). The relationship of the population of $\mathrm{Th}^{+}$ 
Table IV. Lectin Reactivity of Erythrocytes after Treatment with Sialidase

\begin{tabular}{|c|c|c|c|c|c|c|c|c|}
\hline \multirow[b]{2}{*}{ Erythrocytes } & \multirow{2}{*}{$\begin{array}{l}\text { ABO } \\
\text { blood } \\
\text { group }\end{array}$} & \multirow[b]{2}{*}{ Lectins } & \multicolumn{6}{|c|}{$\begin{array}{l}\text { Sialidase treatment } \\
\quad(1 \mathrm{mU} / \mathrm{ml})\end{array}$} \\
\hline & & & 0 & 10 & 30 & 60 & 90 & 120 \\
\hline & & & & & & $\operatorname{nin}$ & & \\
\hline \multicolumn{9}{|l|}{ PNH } \\
\hline \multirow[t]{2}{*}{ patient 1} & $\mathrm{O}$ & Arachis hypogaea & - & $3+$ & $4+$ & $4+$ & $4+$ & $4+$ \\
\hline & & Glycine soja & - & - & - & - & - & + \\
\hline \multirow[t]{2}{*}{ patient 2} & $\mathrm{O}$ & Arachis hypogaea & - & $3+$ & $4+$ & $4+$ & $4+$ & $4+$ \\
\hline & & Glycine soja & - & - & - & - & - & $2+$ \\
\hline \multirow[t]{2}{*}{ patient 3} & A & Arachis hypogaea & - & $3+$ & $4+$ & $4+$ & $4+$ & $4+$ \\
\hline & & Glycine soja & - & - & - & - & - & + \\
\hline \multicolumn{9}{|l|}{ Healthy } \\
\hline \multirow[t]{2}{*}{ control* } & $\mathbf{O}$ & Arachis hypogaea & - & + & $3+$ & $4+$ & $4+$ & $4+$ \\
\hline & & Glycine soja & - & - & - & - & - & - \\
\hline
\end{tabular}

* Representative of four healthy donors.

erythrocytes and Th-agglutination grade was roughly: $0 \%,-$; $10 \%,+; 20 \%, 2+; 40 \%, 3+;>80 \%, 4+$.

Th-induced hemolysis. The standard curves prepared with PNH and control erythrocytes were identical (Fig. 2 B), as expected from the results of a previous report (16). The standard curve showed a linear relation, with a range of $0-20 \%$ hemolysis. On the basis of this relation, $\mathrm{OD}_{540}$ was converted to percent hemolysis. A time course analysis of the in vitro hemolysis with $\mathrm{Th}^{+}$erythrocytes from the patient who experienced the hemolytic episode (patient 1, Table IV, and Fig. 2) showed that a 6-h incubation led to $\sim 50 \%$ hemolysis of the maximum level given by a $24-\mathrm{h}$ incubation. The hemolytic contribution of Th expression was then evaluated by a 6-h incubation in the subsequent hemolysis assays; we found that Thexpression on PNH erythrocytes induced marked hemolysis in autologous serum (Fig. $2 \mathrm{~A}$ ). Such hemolysis was not observed in the serum of blood type-matched cord blood. Two-color flow cytometry showed not only the sialidase-induced expression of Th on all the erythrocytes from both the PNH patient described in the profile (patient 1) and the healthy donor, but also the preferential hemolysis of $\mathrm{Th}^{+} / \mathrm{CD} 59^{-}$erythrocytes in autologous serum (Fig. 3). Serum treatment reduced to some extent the binding of FITC-conjugated Arachis hypogaea to PNH and control erythrocytes (Fig. 3). On the other hand, the hemolysis of $\mathrm{Th}^{-}$erythrocytes from PNH patients was very weak and seemed to be dependent on the population of CD59- erythrocytes (Fig. $2 \mathrm{~A}$, columns 1,3 , and 5 ). Complement-inactivation abolished all the hemolysis. The cause of the minute hemolysis of $\mathrm{Th}^{-} \mathrm{PNH}$ cells was then considered to be nonspecific activation of complement in vitro. The expression of Th on control erythrocytes did not induce their hemolysis (Fig. $2 \mathrm{~A}$, column 8; Fig. 3). No expression of cryptantigen $\mathrm{T}$ was observed throughout the hemolysis assay. These findings support the results shown in Table III. We have presented our findings with the anti-CD59 mAb, which was used to discriminate PNH cells, since CD59 deficiency contributes more predominantly to hemolysis than DAF-deficiency in PNH (18). However, experiments with the anti-DAF mAb gave results consistent with those for the anti-CD59 mAb (data not shown).

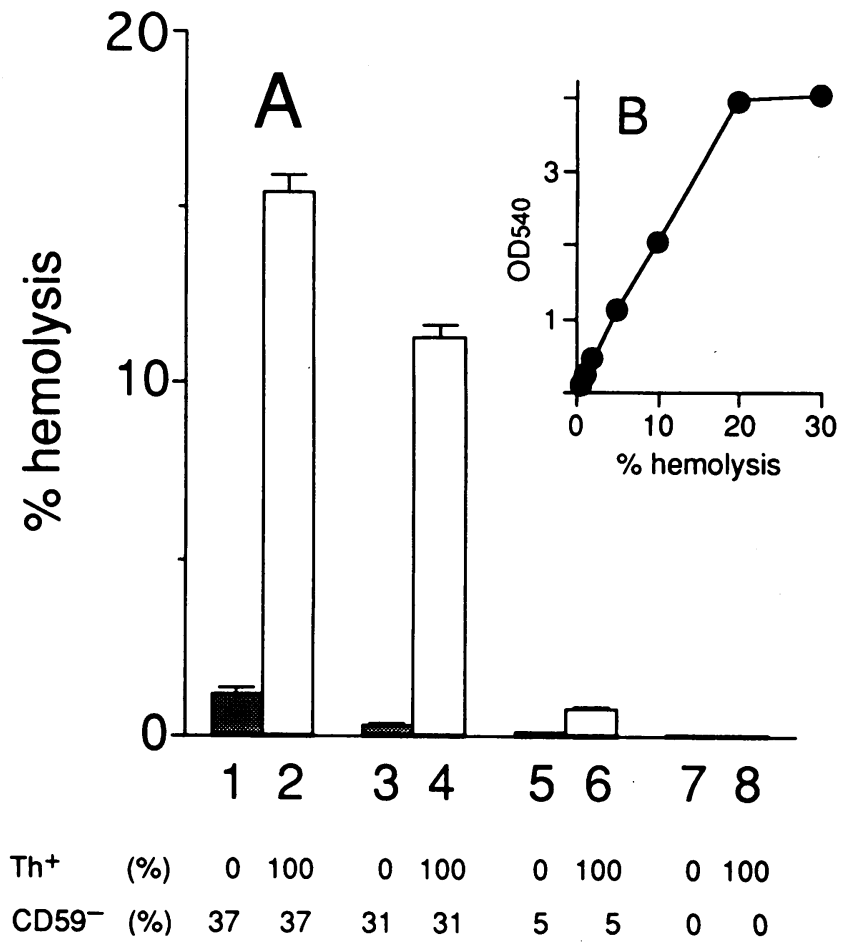

Figure 2. Th expression and hemolysis in vitro. After disclosing cryptantigen Th on PNH patients' erythrocytes, the erythrocytes were incubated with autologous serum for $6 \mathrm{~h}$. The extent of hemolysis was determined from the liberated hemoglobin $\left(\mathrm{OD}_{540}\right)$, using a standard curve (B). Columns 1 and 2 , cells from patient 1 ; columns 3 and 4 , cells from patient 2; columns 5 and 6 , cells from patient 3; columns 7 and 8 , cells from representative of four healthy donors. Columns $2,4,6$, and 8 , cells treated with sialidase; columns $1,3,5$, and 7 , nontreated cells. Each value represents the mean $( \pm S D)$ of triplicate determinations.

\section{Discussion}

In our investigation of the similarity between PNH and Tn syndrome $(1,10,19,20)$, we expected the involvement of cryptantigens in intravascular hemolysis in PNH and actually detected cryptantigen Th on the erythrocytes of a PNH patient who was suffering from infection-induced hemolytic precipitation. Similar to sialidase, the patient's serum obtained at the time of the hemolytic precipitation induced Th on erythrocytes in vitro. The induction of Th on erythrocytes led to marked and preferential hemolysis of PNH erythrocytes in autologous serum in vitro. These in vitro findings, taken together with the close correlation noted here between in vivo hemolysis, the decrease of CD59- erythrocytes, and Th-agglutination (Fig. 1), indicate the selective hemolysis of $\mathrm{Th}^{+} \mathrm{PNH}$ cells in the hemolytic precipitation. The in vitro hemolysis was observed in neither complement-inactivated serum nor blood type-matched cord blood serum, which lacks natural antibodies to cryptantigens ( 8 , $10,11)$. Moreover, in vitro hemolysis tests with the erythrocytes obtained from seven PNH patients gave results consistent with those noted above (data not shown). Th-associated hemolysis was further observed in another PNH patient with a common cold and herpes. We thus conclude that the infection-associated expression of Th on erythrocytes induced the immune reaction of Th with natural antibody, leading to complement activation on the erythrocytes, and contributing to the intravascular hemolysis. 

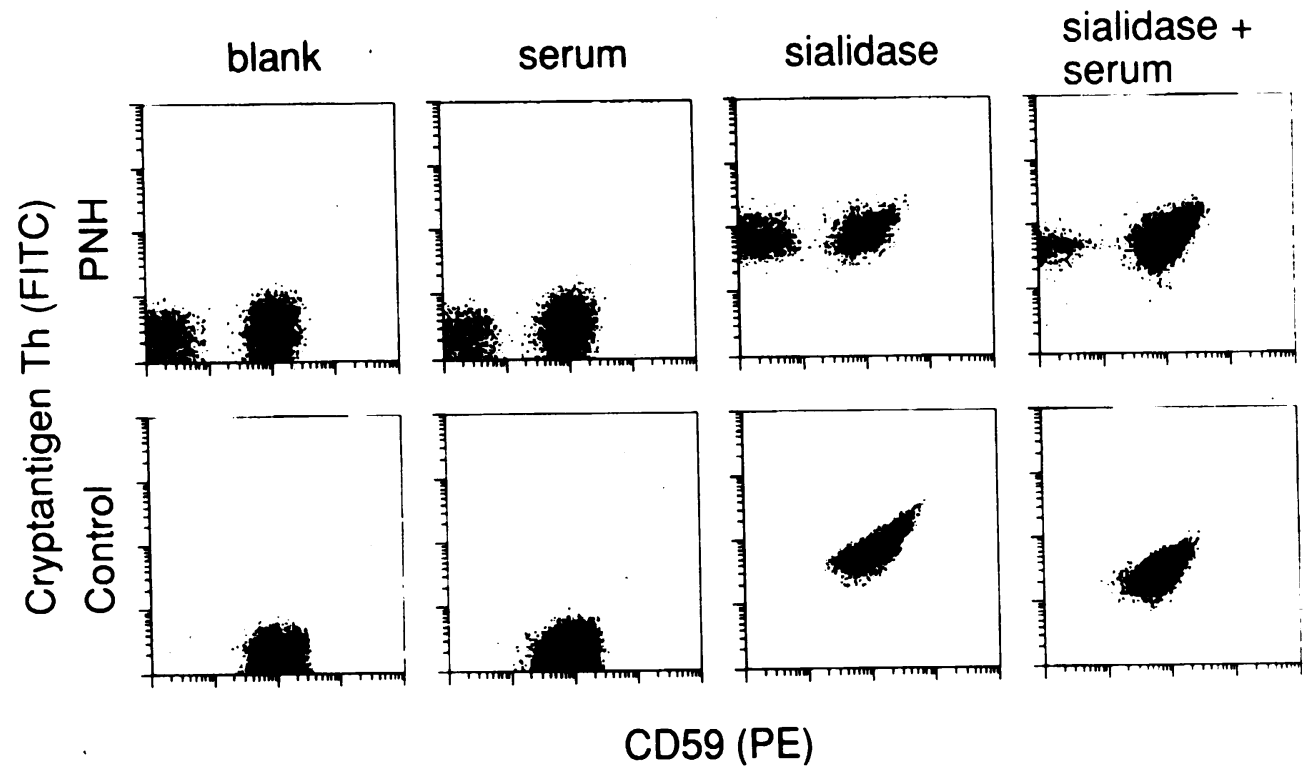

Figure 3. Two-color analysis of erythrocytes after Th induction and hemolysis. With sialidase ( 1 $\mathrm{mU} / \mathrm{ml}, 60 \mathrm{~min}$ ), Th was induced on the erythrocyes from patient 1 $(P N H)$ and on those of the healthy donor (Control). The treated cells (sialidase) and untreated cells (blank) were incubated with autologous serum for $6 \mathrm{~h}$, and then analyzed by flow cytometry with FITC-conjugated Arachis hypogaea lectin to label Th and PEconjugated anti-CD59 $\mathrm{mAb}$.

Regarding the cryptantigen-associated precipitation (CAP) of hemolysis, the intensity of hemolysis may be principally defined by the desialylation activity, the population of PNH erythrocytes, and the titer of natural antibody to Th (2). These three factors are, respectively, associated with infections, hematopoietic stimulation with iron, and blood transfusions that are notorious for their precipitation of hemolysis in PNH (4). In regard to the frequency of Th exposure in vivo, the ease with which this exposure is brought about by the release of a small amount of sialic acid from the erythrocyte membrane in vitro implies that Th expression is relatively common in vivo $(8,15$, 21-27). Actually, the expression of Th on erythrocytes without hemolysis has often been found recently in patients with viral infection, leukemia, myelodysplastic syndrome, and aplastic anemia in our hospital, but in none of healthy volunteers. The cryptantigen possibly serves as a marker of denatured cells for clearance by the immune system. In addition to Th expression, we further noted the expression of another cryptantigen $T$ in recent hemolytic episode on the erythrocytes from a 72-yrold woman with PNH. As expected, induction of T on PNH erythrocytes with sialidase (15) also led to a striking hemolysis in vitro, whereas the expression of $\mathrm{T}$ on control erythrocytes did not induce such hemolysis (Fig. 4). Thus, we propose that the cryptantigen-mediated immune reaction with natural antibody on affected erythrocytes is one of the potential sources of the intravascular activation of complement in PNH hemolysis.

With regard to the clinical applications of these findings, it is prudent to detect cryptantigens (at least Th and T) on PNH erythrocytes for the prediction of CAP hemolysis. Regarding therapy, transfusion with washed erythrocytes is often used after hemolytic episodes to improve anemia, inhibit the anemia-induced feedback stimulation of hematopoiesis by mutated stem cell, and consequently decrease the population of PNH erythrocytes. From our findings, it is also conceivable that cryptantigen expression activity in serum would be partly directed to the healthy transfused erythrocytes, and the cells which then become cryptantigen-positive would take up natural antibodies without obvious intravascular hemolysis. That is, the three factors in CAP hemolysis are expected to be diminished by the transfusion. The earlier the transfusion is begun, the more effec- tive the treatment would be. In our patient, the transfusion was initiated for the treatment of rapidly progressed anemia, and then too late to exert the complete effects. To establish clinical benefit of the early transfusion, however, a large scale of followup study of the relation between the population of cryptantigenpositive PNH erythrocytes and intravascular hemolysis is indispensable. As another application of these findings, attention should be paid to the hemolytic exacerbation induced by transfusion with blood products contaminated by natural antibodies,

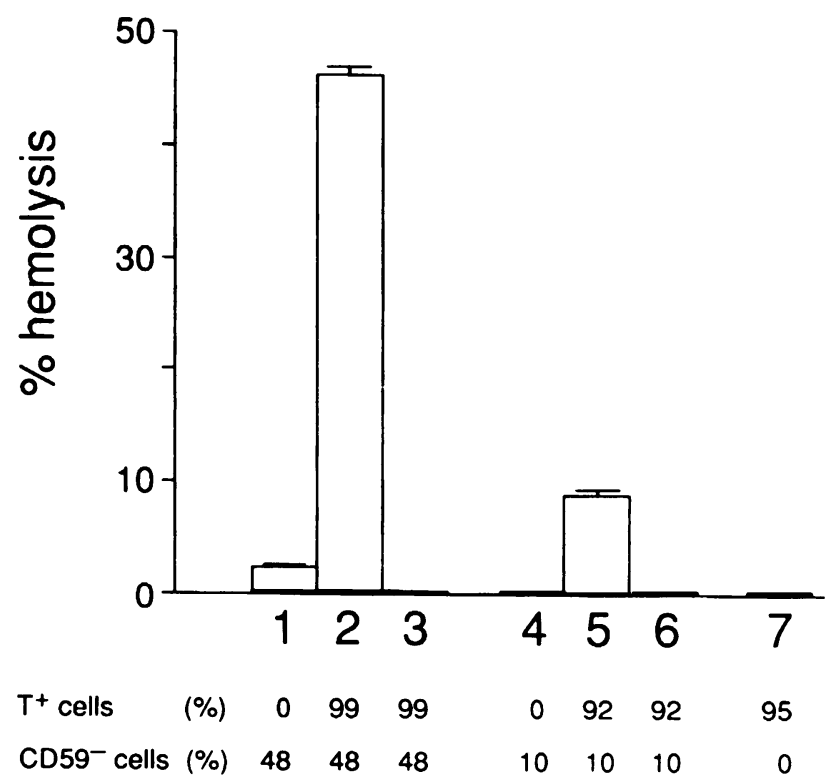

Figure 4. $\mathrm{T}$ expression and hemolysis in vitro. Cryptantigen $\mathrm{T}$ was induced on the erythrocytes from a PNH patient (columns 1-3), another patient (columns 4-6), and healthy donor (column 7) by the treatment with sialidase $(100 \mathrm{mU} / \mathrm{ml})$ at $37^{\circ} \mathrm{C}$ for $60 \mathrm{~min}$. The cells were then incubated with autologous serum for $4 \mathrm{~h}$. Columns 1 and 4 , sialidaseuntreated erythrocytes; columns 3 and 6 , complement-inhibited serum with $5 \mathrm{mM}$ EDTA and EGTA. Each value represents the mean ( \pm SD) of triplicate determinations. 
especially in PNH patients with erythrocytes expressing cryptantigens (12).

Other noteworthy findings were that: (a) Arachis hypogaea aggregated the granulocytes obtained from the patient at the time of the hemolytic precipitation, as inferred from a previous report on the exposure of cryptantigen $T$ on leukocytes and platelets (28), while sialidase treatment enhanced granulocyte aggregation in autologous serum (data not shown). However, the decrease of leukocytes in the peripheral blood was not confirmed. It is conceivable that infection-stimulated mobilization of leukocytes masked their decrease. (b) Although $\mathrm{Th}^{+}$platelets were not demonstrable in our patient, the role played by cryptantigens on platelets could be of interest in the development of thrombosis which partly shares the causes with episodic hemolysis in PNH (4). Further, the more rapid appearance of cryptantigens on PNH erythrocytes than on control cells in the treatment with sialidase may reflect the increased susceptibility of PNH cells to the enzyme due to structural changes in erythrocyte membrane $(5,19,29)$ representing the hemolytic diathesis of PNH cells.

Moreover, although PNH hemolysis has been generally accepted to be negative for direct Coombs' test, some erythrocytes in CAP hemolysis may be positive for the test, judging from a report that the erythrocytes were Coombs' positive in cryptantigen-associated hemolytic uremic syndrome (30). It is conceivable that the Coombs' test, which preferably reacts with human IgG and C3d component of complement $(7,13)$, may not be sensitive enough to detect the relatively small amounts of natural antibody and complement that are required to hemolyze PNH erythrocytes (2).

Taken together with the metabolic alteration of sugar chains of gangliosides $(16,29)$ and glycosylphosphatidylinositol anchor (5), the appearance of cryptantigens suggests that the structural modification of membrane carbohydrates plays a critical role in the pathogenesis of PNH.

\section{Acknowledgments}

We thank Drs. Makoto Kawakita and Tetsuro Yamamoto of Kumamoto University School of Medicine for their advice and help, and Ms. Fumi Inukai for secretarial assistance.

This work was supported in part by grants from the Ministry of Education, Science and Culture of Japan, Yamanouchi Foundation for Research on Metabolic Disorders, and Ono Medical Foundation.

\section{References}

1. Rotoli, B., and L. Luzzatto. 1989. Paroxysmal nocturnal hemoglobinuria. Semin. Hematol. 26:201-207.

2. Rosse, W. F. 1993. Evolution of clinical understanding: paroxysmal nocturnal hemoglobinuria as a paradigm. Am. J. Hematol. 42:122-126.

3. Rosse, W. F. 1993. The glycolipid anchor of membrane surface proteins. Semin. Hematol. 30:219-231.

4. Lee, G. R. 1993. Paroxysmal nocturnal hemoglobinuria. In Wintrobe's Clinical Hematology. G. R. Lee, T. C. Bithell, J. Foerster, J. W. Athens, J. N. Lukens, editors. Lea \& Febiger, Philadelphia/London, 9th ed. 1232-1244.

5. Hidaka, M., S. Nagakura, K. Horikawa, T. Kawaguchi, N. Iwamoto, T. Kagimoto, K. Takatsuki, and H. Nakakuma. 1993. Impaired glycosylation of glycosylphosphatidylinositol anchor synthesis in paroxysmal nocturnal hemoglobinuria leukocytes. Biochem. Biophys. Res. Commun. 191:571-579.
6. Miyata, T., N. Yamada, Y. Iida, J. Nishimura, J. Takeda, T. Kitani, and T. Kinoshita. 1994. Abnormalities of $P I G-A$ transcripts in granulocytes from patients with paroxysmal nocturnal hemoglobinuria. N. Engl. J. Med. 330:249-255.

7. Dacie, J. 1992. The auto-immune haemolytic anaemias. In The Haemolytic Anaemias. J. Dacie, editor. Churchill Livingstone, Edinburgh, United Kingdom 3rd ed. $528 \mathrm{pp}$.

8. Judd, W. J. 1992. Review: polyagglutination. Immunohematology. 8:5869.

9. Bird, G. W. G. 1990. Some aspects of serological specificity. Transfusion (Bethesda). 30:390-399.

10. Levene, C., N. A. Levene, D. Buskila, and N. Manny. 1988. Red cell polyagglutination. Transfus. Med. Rev. 2:176-185.

11. Dacie, J. 1992. Polyagglutinability and haemolytic anaemia. In The Haemolytic Anaemias. J. Dacie, editor. Churchill Livingstone, Edinburgh, United Kingdom. 3rd ed. 201-204.

12. Novak, R. W. 1990. The pathobiology of red cell cryptantigen exposure. Pediatr. Pathol. 10:867-875.

13. Walker, R. H. 1993. Technical Manual. 11th edition American Association of Blood Banks, Bethesda, MD. 790 pp.

14. Moulds, J. J. 1980. Polyagglutination: overview and resolution, Appendices I-VI. In Polyagglutination: A Technical Workshop. M. L. Beck and W. J. Judd, editors. American Association of Blood Banks, Washington DC. 12-17.

15. Sondag-Thull, D., N. A. Levene, C. Levene, N. Manny, Y. W. Liew, G. W. G. Bird, Y. Schechter, C. Francois-Gerard, M. Huet, and D. Blanchard. 1989. Characterization of a neuraminidase from Corynebacterium aquaticum responsible for Th polyagglutination. Vox Sang. 57:193-198.

16. Horikawa, K., H. Nakakuma, S. Nagakura, M. Kawakita, T. Kagimoto, M. Iwamori, Y. Nagai, T. Abe, and K. Takatsuki. 1991. Hemolysis of human erythrocytes is a new bioactivity of gangliosides. J. Exp. Med. 174:1385-1391.

17. Nagakura, S., T. Kawaguchi, K. Horikawa, M. Hidaka, N. Iwamoto, T. Kagimoto, K. Takatsuki, and H. Nakakuma. 1993. A deficiency in CDw52 (CAMPATH-1 antigen) of paroxysmal nocturnal hemoglobinuria lymphocytes. Blood. 82:3790-3792.

18. Yamashina, M., E. Ueda, T. Kinoshita, T. Takami, A. Ojima, H. Ono, H. Tanaka, N. Kondo, T. Orii, N. Okada et al. 1990. Inherited complete deficiency of 20-kilodalton homologous restriction factor (CD59) as a cause of paroxysmal nocturnal hemoglobinuria. $N$. Engl. J. Med. 323:1184-1189.

19. Parker, C. J., C. M. Soldato, and W. F. Rosse. 1984. Abnormality of glycophorin- $\alpha$ on paroxysmal nocturnal hemoglobinuria erythrocytes. J. Clin. Invest. 73:1130-1143.

20. Thurnher, M., J. Fehr, and E. C. Berger. 1994. Differences in the regulation of specific glycosylation in the pathogenesis of paroxysmal nocturnal hemoglobinuria and Tn-syndrome. Exp. Hematol. 22:267-271.

21. Janvier, D., F. Guignier, M. Reviron, and M. Benbunan. 1991. Concomitant exposure of $\mathrm{Tn}$ and Th cryptantigens on the red cells of a patient with myelodysplasia. Vox Sang. 61:142-143.

22. Levene, N. A., C. Levene, K. Gekker, E. Sigler, H. Merhav, and A. Berrebi. 1990. Th polyagglutination with fatal outcome in a patient with massive intravascular hemolysis and perforated tumor of colon. Am. J. Hematol. 35:127128.

23. Buskila, D., C. Levene, H. Biran, and N. A. Levene. 1988. Exposure of cryptantigens on erythrocytes in patients with breast cancer. Cancer. 61:24552459.

24. Herman, J. H., W. Whiteheart, R. S. Shirey, R. J. Johnson, T. S. Kickler, and P. M. Ness. 1987. Red cell Th activation: biochemical studies. Br. J. Haematol. 65:205-209.

25. Herman, J. H., R. S. Shirey, B. Smith, T. S. Kickler, and P. M. Ness. 1987. Th activation in congenital hypoplastic anemia. Transfusion (Bethesda). 27:253-256.

26. Okubo, Y., T. Seno, and H. Yamaguchi. 1984. A persistent type of erythrocyte polyagglutinability Th. Transfusion (Bethesda). 24:277-278.

27. Bird, G. W. G., J. Wingham, M. L. Beck, S. R. Pierce, G. D. Oates, and A. Pollock. 1978. Th, a "new" form of erythrocyte polyagglutination. Lancet i:1215-1216.

28. Hysell, J. K., J. W. Hysell, M. E. Nichols, R. G. Leonardi, and W. L. Marsh. 1976. In vivo and in vitro activation of T-antigen receptors on leukocytes and platelets. Vox Sang. 31:9-15.

29. Nakakuma, H., T. Kawaguchi, K. Horikawa, M. Hidaka, Y. Yonemura, M. Kawakita, T. Kagimoto, M. Iwamori, Y. Nagai, and K. Takatsuki. 1990. Altered expression of gangliosides in erythrocytes of paroxysmal nocturnal hemoglobinuria. J. Clin. Invest. 85:1456-1461.

30. Feld, L. G., J. E. Springate, R. Darragh, and R. D. Fildes. 1987. Pneumococcal pneumonia and hemolytic uremic syndrome. Pediatr. Infect. Dis. J. 6:693695. 